\title{
Reflexões jurídicas acerca das novas terapias em saúde: uma análise à luz da lei de biossegurança
}

\section{Juridical reflections on new health therapies: an analysis in the light of the biosafety law}

\author{
Manoel Antônio dos Santos Neto \\ Procuradoria Geral do Estado, Pernambuco, Brasil \\ manoel.neto@pge.pe.gov.br
}

Resumo: Este trabalho discorre sobre aspectos jurídicos ligados às novas terapias em saúde, fazendo uma análise em consonância com o ordenamento jurídico brasileiro, com enfoque predominante sobre a Lei de Biossegurança. Aduz sobre a necessidade do consentimento informado do paciente sempre que os procedimentos terapêuticos ou pesquisas envolvam a utilização de seu material biológico, além da necessária observância do princípio da precaução. Aborda o tema das patentes envolvendo células-tronco embrionárias, a partir de uma comparação entre a realidade americana e o direito brasileiro. Destaca ainda importantes aspectos penais constantes na Lei de Biossegurança, os quais tutelam o direito a individualidade genética e a dignidade da pessoa humana.

Palavras-chave: Biossegurança. Patentes. Consentimento Informado. Princípio da Precaução. Dignidade da Pessoa Humana.

\begin{abstract}
This study discusses juridical issues relating to new health therapies through an analysis consonant with the Brazilian legal system, focusing mainly on the Biosafety Law. It shows that there is a need for informed consent from patients whenever the therapeutic procedures or investigations involve use of their biological material, as well as the need to observe the precautionary principle. It covers the topic of patents involving embryonic stem cells, from a comparison between American realities and Brazilian law. It also highlights important penal aspects of the Biosafety Law that protect the right to genetic individuality and dignity of the human person.
\end{abstract}

Keywords: Biosafety. Patents. Informed consent. Precautionary principle. Dignity of the human person. 


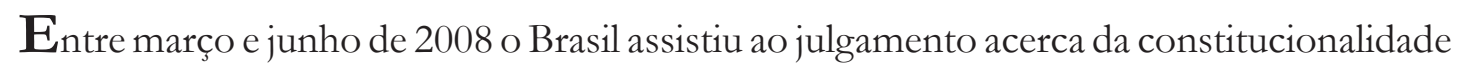
do artigo $5^{\circ}$ da Lei de Biossegurança - lei n. ${ }^{\circ} 11105$ de 24 de março de $2005^{1}$ (1) - o qual permitiu que células-tronco embrionárias, obtidas a partir de fertilização in vitro e não utilizadas no respectivo procedimento, fossem destinadas às pesquisas e terapias em saúde.

Vários foram os argumentos favoráveis e contrários ao referido uso. Dentre os argumentos contrários, destacaram-se os seguintes: o questionamento se tal procedimento, do ponto de vista jurídico-penal, se equivaleria ao aborto; além do ressurgimento de antigas discussões, não só jurídicas, mas multidisciplinares, sobre o início da vida humana e limites éticos para as pesquisas científicas.

Dentre os pontos favoráveis às novas práticas terapêuticas em saúde, os quais prevaleceram, merece destaque a própria ideia de esperança de descoberta de cura para algumas enfermidades, mediante o progresso da ciência; além da retomada do debate bioético, em conformidade com a dignidade da pessoa humana, que deve preponderar em qualquer procedimento terapêutico (2).

No presente trabalho, retomaremos as discussões sobre os limites jurídicos entre a vida e a morte; perpassaremos sobre o debate acerca da não-obrigatoriedade de implantação de todos os embriões fertilizados, em consonância com o princípio constitucional do planejamento familiar, além de fazermos uma abordagem sobre o aparato jurídico-normativo constante na Lei de Biossegurança, com suas normas permissivas, proibitivas e respectivas sanções, inclusive no âmbito penal, o qual nos permite falar em parâmetros ético-jurídicos a serem seguidos no desenvolvimento de novas terapias em saúde.

\section{Dos limites jurídicos entre a vida e a morte}

Partindo-se da vida para a morte, tem-se que a existência física do ser subsiste enquanto não lhe sobrevenha o óbito encefálico, momento a partir do qual é permitida à equipe médica independente - mediante autorização familiar - a remoção de órgãos e tecidos para fins de transplante.

Em que pese ser um conceito científico, empiricamente aferido, a constatação

1. Lei $11105 / 2005$, Art. $5^{\circ}$ : "É permitida, para fins de pesquisa e terapia, a utilização de células-tronco embrionárias obtidas de embriões humanos produzidos por fertilização in vitro e não utilizados no respectivo procedimento, atendidas as seguintes condições: I - sejam embriões enviáveis; ou II - sejam embriões congelados há 3 (três) anos ou mais [...] \ $1^{\circ}$ Em qualquer caso é necessário o consentimento dos genitores.” 
da morte tem repercussões jurídicas, daí haver um aparato normativo a corroborar a cessação da vida a partir do término da função encefálica, momento em que haveria um limite de ação juridicamente permitido para práticas, também terapêuticas, a partir da remoção de órgãos. Afere-se, portanto, a relevância do diagnóstico morte, seja do ponto de vista biológico ou seja sob o aspecto jurídico.

No Brasil, a previsão normativa da morte encefálica encontra guarida na lei $n^{\circ} .9434 / 97^{2}$, mais especificamente em seu artigo $3^{\circ}$ (3). Correlacionando a existência de atividade encefálica com a própria ideia de existência de vida é que os tribunais pátrios já autorizaram a retirada de fetos anencéfalos do útero materno, em que pese não haver nenhuma autorização normativa expressa ${ }^{3}$ (4). Partindo-se da premissa de que a existência da vida requer atividade encefálica, pode-se concluir, mediante a técnica da argumentação a contrario sensu (5), que as células-tronco embrionárias - dada a ausência de massa encefálica - não se enquadram, ao menos sob o prisma jurídico, no conceito de vida humana.

Destarte, a utilização de células-tronco para fins terapêuticos ou de pesquisa também não pode ser equiparada à prática de aborto, uma vez que tal delito, para consumar-se, necessita da existência de um ser pré-natal, no interior do corpo feminino, o que não é o caso, haja vista o fato de tais células embrionárias serem frutos de uma fertilização in vitro, as quais não serão mais implantadas no útero materno.

O ordenamento constitucional brasileiro elenca a dignidade da pessoa humana como valor fundamental da República Federativa (art. $1^{\circ}$, III), assim como o próprio direito a vida (art. $5^{\circ}$, caput) (6). Destaque-se, outrossim, que não há direitos fundamentais absolutos, os quais poderão eventualmente colidir, no momento da aplicação da norma. Ao aplicador do direito, por sua vez, caberá exercer uma atividade de ponderação (7) de modo que haja o mínimo de sacrifício dos bens jurídicos postos em colisão. Neste diapasão, a própria vida, já possuindo atividade encefálica, poderá vir a ser suprimida em alguns casos expressos em lei. O código penal brasileiro, por exemplo, é expresso, quando, em seu artigo $128^{4}$ (8), deixa de criminalizar duas hipóteses de aborto: o aborto necessário, quando não há outro meio de salvar a vida da gestante; bem como o caso

2. Lei $9434 / 97$, Art. $3^{\circ}$, caput: "A retirada post mortem de tecidos, órgãos ou partes do corpo humano destinados a transplante ou tratamento deverá ser precedida de diagnóstico de morte encefálica, constatada e registrada por dois médicos não participantes das equipes de remoção e transplante, mediante a utilização de critérios clínicos e tecnológicos definidos por resolução do Conselho Federal de Medicina".

3. Tal questão restou pacificada pelo Supremo Tribunal Federal, com a conclusão do julgamento da Ação de Descumprimento de Preceito Fundamental (ADPF) de n 54, em 12 de abril de 2012, oportunidade em que a Corte concluiu pela possibilidade de interrupção da gestação de feto anencéfalo.".

4. Código Penal, Art. 128: "Não se pune o aborto praticado por médico: I - se não há outro meio de salvar a gestante; II - se a gravidez resulta de estupro e o aborto é precedido de consentimento da gestante ou, quando incapaz, de seu representante legal." 
de gravidez decorrente de estupro, mediante consentimento da gestante ou de seu representante legal.

O Código Civil brasileiro, por seu turno, dispõe, em seu artigo $2^{\circ}$, que “a personalidade civil da pessoa começa com o seu nascimento com vida; mas a lei põe a salvo, desde a concepção, os direitos do nascituro" (9). Da análise do dispositivo legal percebe-se que o nascituro seria um sujeito de direitos em condição suspensiva, já que a fruição de seus direitos condiciona-se ao seu efetivo nascimento. Observa-se ainda que o legislador não criou dispositivos desprovidos de significados, já que, se a lei resguarda direitos desde a concepção, isso significa que o período gestacional de vida intrauterina merece total proteção estatal, já gozando o feto da proteção constitucional inerente à dignidade da pessoa humana. Tamanha é a proteção jurídica conferida ao feto que o código penal tipifica como crime, salvo as duas exceções anteriormente citadas, a prática de aborto. Não se pode ignorar, entretanto, que após o nascimento com vida o ordenamento jurídico protege ainda mais o indivíduo, tanto é que o término da vida por fato de outrem, após o nascimento, é reprimido com a pena de homicídio, a qual é superior a de aborto.

Note-se que o nascimento com vida é marco divisor no Direito no que se refere à amplitude da proteção à dignidade da pessoa humana. O código penal, por exemplo, descriminaliza o aborto, conforme se destacou, em caso de gravidez decorrente de estupro (com consentimento da gestante ou de seu representante legal, se incapaz). Entretanto, se o nascituro vem a nascer vivo, ainda que fruto de relação sexual obtida através de estupro, não há mais permissivo legal para ceifá-lo a vida, já que aquele ato que, em meses anteriores, enquadrar-se-ia no conceito de aborto legalmente permitido, passa, após o nascimento, a qualificar-se como homicídio ou infanticídio - se praticado pela mãe sob influência de estado puerperal.

Ante o exposto, entende-se que a proteção ao nascituro como sujeito de direitos, inclusive submetido à dignidade da pessoa humana, se dá a partir de sua implantação no ventre materno, destacando-se que tal proteção ocorre de forma progressiva, tomando uma máxima eficácia após o nascimento com vida.

\section{Do fundamento constitucional do planejamento familiar. Do consentimento informado dos genitores}

A Constituição Federal em seu artigo 226, $\$ 7^{\circ}$ (6), veda a interferência coercitiva 
do Estado em se tratando de planejamento familiar ${ }^{5}$, o qual é fruto de livre decisão do casal. Neste diapasão, levando-se o debate ao tema central do presente trabalho, observase que não há uma obrigatoriedade de implantação de todos os embriões obtidos a partir de fertilização in vitro, caso contrário estaria o Estado a interferir diretamente na organização das famílias, coagindo as mulheres a implantar todos os embriões fertilizados, o que não encontra guarida na ordem constitucional vigente.

Não havendo obrigatoriedade, conforme exposto, de implantação de todos os embriões fertilizados in vitro, observou-se que muitas células-tronco seriam, inexoravelmente, descartadas, sem que tal descarte implicasse qualquer cometimento de delito. O legislador infraconstitucional, por seu turno, veio a regular a utilização das células totipotentes, não implantadas no útero materno, para fins de pesquisa e terapia. Dentre os requisitos para o desenvolvimento dos trabalhos científicos, a lei destacou a necessidade de que os embriões utilizados fossem inviáveis ou que tivessem sido congelados há mais de três anos, além do consentimento informado dos genitores.

O último requisito citado - o consentimento informado - encontra correspondente na jurisprudência americana, sobretudo após o leading case "Moore v. Regents of Califórnia" (10). Tal caso teve início com a utilização econômica, mediante o patenteamento, não autorizado, de uma linhagem celular elaborada a partir de tecidos do baço do americano John Moore. Moore era portador de leucemia e teve o baço retirado no curso de seu tratamento. Médicos que o acompanhavam descobriram, na Universidade da Califórnia (UCLA), que os tecidos do baço eram aptos a produzir singular proteína do sangue. A posteriori, Moore assinou algumas declarações de consentimento apenas com os pesquisadores da universidade, entretanto, à revelia do paciente, a universidade e seus pesquisadores firmaram contrato com as sociedades Genetic e Sandoz, as quais patentearam nove medicamentos contra bactérias e contra o câncer. Quando tomou ciência da situação, Moore acionou em juízo a Universidade da Califórnia, solicitando coparticipação nos lucros, além de ressarcimento pela quebra da relação de confiança entre médico e paciente. A suprema corte americana indeferiu o pleito de participação nos lucros, mas condenou a universidade em indenização referente à quebra da relação de confiança, o que fez ressurgir a necessidade do consentimento do paciente para pesquisas com a utilização secundária de seu material biológico.

No Brasil, o consentimento dos genitores mostra-se como um requisito indispensável à utilização de células embrionárias para fins terapêuticos ou de pesquisa,

5. Código Penal , Art. 128: "Não se pune o aborto praticado por médico: I - se não há outro meio de salvar a gestante; II - se a gravidez resulta de estupro e o aborto é precedido de consentimento da gestante ou, quando incapaz, de seu representante legal." 
vedando-se inclusive a comercialização de tais células, fruto da fertilização in vitro. Fez por bem o legislador pátrio em estabelecer a premissa do consentimento informado associada à vedação de comercialização do material biológico, uma vez que não se pode olvidar que é crescente o fenômeno da patrimonialização dos direitos da personalidade. Sabe-se que as pesquisas científicas com informações sobre o corpo humano, além das disputas pelas patentes, adquiriram um valor comercial que ultrapassa os limites da mera utilização terapêutica (10).

Apesar de a necessidade de consentimento ser hoje uma questão aparentemente pacífica para o Direito, havia, durante o século XX, duas correntes sobre o tema: a realista e a personalista (10). A doutrina realista alemã, em breves linhas, entendia que o corpo humano, considerado como um todo indivisível, não poderia ser encarado como objeto de propriedade. Entretanto, surgiria um direito real de propriedade sobre as partes do corpo humano após a sua remoção, como se fora frutos derivados de uma árvore. A referida teoria teve como consequência a desnecessidade do consentimento, sempre que os materiais biológicos fossem frutos de um perceptível abandono, como é o caso dos resíduos pós-operatórios ou dos cabelos após o seu corte, desde que o paciente não manifestasse mais interesse em possuí-los. Para os personalistas, doutrina atualmente prevalecente, inclusive nas legislações nacional e internacional, cabe ao indivíduo não só ter ciência, mas também consentir com a destinação futura dos resquícios de seu material biológico. A visão personalista considera a unicidade do indivíduo, respeitando a sua vontade manifestada em momento anterior à separação de seu material biológico.

A medicina tenta alargar ao máximo a manutenção da vida humana, cessando a intervenção médico-curativa com a morte do paciente; o direito, a seu turno, tenta conservar ao máximo o âmbito da autonomia da vontade individual, a qual, frise-se, produz efeitos que se estendem temporalmente para além da vida, como é o caso da proteção jurídica que se confere a um testamento ou declarações de última vontade. Sem o consentimento prévio, não há que ter guarida qualquer utilização do ser humano enquanto instrumento de pesquisas.

\section{A realidade americana e a vedação à concessão de patentes de células-tronco humanas no Brasil}

No direito brasileiro, dentre os requisitos gerais para o patenteamento de um produto, há que se observar se estão presentes os requisitos da novidade, da atividade inventiva e da aplicação industrial ${ }^{6}$ (11). Destaque-se que os chamados modelos de 
utilidade, entendidos como aqueles instrumentos que aperfeiçoam o uso de um objeto pré-existente, também podem ser objeto de patenteamento (11). Meras descobertas, já presentes na natureza, em tese não deveriam ser objeto ${ }^{7}$ de patentes, uma vez que não são frutos de atividade inventiva, mas são apenas revelações daquilo que já existia. O direito brasileiro não admite que se patenteie descobertas, pois nelas não se vislumbra o citado requisito da atividade inventiva.

Em que pese tratar-se de descoberta de elemento pré-existente, os Estados Unidos da América foram pioneiros na admissibilidade de patenteamento de célulastronco humanas. Destacou-se, na corrida pelas patentes, o pesquisador James Thompson, que patenteou células tronco-humanas e, em seguida, firmou contrato de licença exclusiva de uso de tais células com a Gera Corporation, empresa privada de biotecnologia que financiava suas pesquisas (11). Ocorre que o patenteamento de um produto confere, por determinado período, o direito exclusivo de utilização, gerando a necessidade de prévio licenciamento de uso conferido pelo seu possuidor, o que restringe e onera o avanço das pesquisas científicas, denotando, no mais das vezes, a prevalência de um interesse econômico em detrimento da coletividade.

A vigente legislação brasileira sobre patentes, conhecida como Lei de Propriedade Industrial, é expressa em vedar o patenteamento de elementos que envolvam o todo ou parte dos seres vivos ${ }^{8}$ (12). Em se tendo como requisito da obtenção da patente - além da atividade inventiva - a aplicação industrial, pode-se afirmar que a Lei de Biossegurança também veda o patenteamento de células embrionárias, uma vez que o $\$ 3^{\circ}$ de seu artigo $5^{\circ}$ (1) proíbe qualquer forma de comercialização do material biológico nele referido , o qual remete às células-tronco embrionárias. A Lei de Biossegurança não só proíbe, mas equipara a comercialização de células embrionárias à venda de órgãos, submetendo o infrator a sanção penal de reclusão de 3 (três) a 8 (oito) anos e multa ${ }^{10}$ (3).

No que se refere ao tema das patentes, pode-se afirmar que o Brasil possui uma legislação avançada, destacando-se no plano internacional, sobretudo quando postas em

aplicação industrial”.

7. Lei 9279/96, Art. 9: "É patenteável como modelo de utilidade o objeto de uso prático, ou parte deste, suscetível de aplicação industrial, que apresente nova forma ou disposição envolvendo ato inventivo, que resulte em melhoria funcional no seu uso ou em sua fabricação".

8. Lei 9279/96, Art. 18, III: "Não são patenteáveis: III - o todo ou parte dos seres vivos (...)"

9. Lei 11105/05, Art. 5, $\int 3^{\circ}$ : "É vedada a comercialização do material biológico a que se refere este artigo e sua prática implica o crime tipificado no art. 15 da Lei n 9434, de 4 de fevereiro de 1997".

10. Lei 9434/97, Art. 15: "Comprar ou vender tecidos, órgãos ou partes do corpo humano: Pena - reclusão, de três a oito anos, e multa, de 200 a 360 dias-multa. Parágrafo único. Incorre na mesma pena quem promove, intermedeia, facilita ou aufere qualquer vantagem com a transação.” 
discussão matérias atinentes à saúde pública, como ocorreu com a quebra de patente para produção de remédios para o tratamento do buman immunodeficiency virus (HIV) (11), em que se observou a supremacia dos direitos humanos, além da prevalência do interesse público sobre o privado.

\section{Das tipificações penais: a vedação jurídica da clonagem humana e o princípio da precaução}

Para além da abordagem sobre as células-tronco embrionárias, o artigo 26 da Lei de Biossegurança é expresso em vedar a clonagem de seres humanos, infligindo pena de reclusão de 2 (dois) a 5 (cinco) anos, além de multa para quem realizá-la. Ainda não há exemplos jurídicos de aplicação de tal norma, talvez por limitações ainda enfrentadas pelo estado da técnica.

Ainda que já houvesse, no Brasil, um arcabouço técnico-científico apto a realizar a clonagem humana, houve por bem o legislador em proibi-la, em harmonia com o princípio da precaução, sobre o qual se passará a tecer algumas considerações.

O princípio da precaução, muito utilizado no campo do Direito Ambiental (13), cuida em evitar a ocorrência de um perigo abstrato, inibindo a prática de atividades cujas consequências podem fugir da seara do previsível. Refoge aos postulados éticos fazer do ser humano um instrumento de pesquisas, sobretudo quando não se pode ter um controle preciso de seus resultados. $\mathrm{O}$ mundo recentemente assistiu à clonagem de uma ovelha realizada pela equipe do Dr. Ian Wilmut (14) - da Escócia - a qual apresentou nítidos sinais de envelhecimento precoce, anteriormente não previstos pelos cientistas. A vedação à clonagem humana, frise-se, é fruto da ideia de precaução, não podendo o homem, tal qual se fez com o animal, submeter-se ao imponderável.

A doutrina afirma que o princípio da precaução não deve ser analisado como aquele que tudo impede ou que em tudo vê males ou catástrofes, mas sobretudo como um princípio que protege a sadia qualidade de vida e durabilidade das gerações. Elencam-se ainda as seguintes características do princípio: incerteza do dano decorrente de uma ação ou inação, em face dos conhecimentos científicos existentes; probabilidade de efeitos graves e irreversíveis ao meio ambiente; o princípio se dirige não só aos particulares, mas principalmente às autoridades públicas (14), no momento da fiscalização e apreciação das autorizações para pesquisas.

Em se procurando uma classificação jurídica para o delito de clonagem humana, chega-se à conclusão de que se trata de um delito instantâneo de efeitos permanentes, 
caracterizado pela índole duradoura de suas consequências (15). Diz-se delito instantâneo porque sua consumação ocorre em um único momento, o qual, in casu, seria o instante do nascimento com vida do clone humano; os efeitos permanentes do delito decorreriam da irreversibilidade da lesão causada, haja vista a impossibilidade do retorno ao status quo anterior ao cometimento do crime. A consequência do crime, a seu turno, seria o nascimento de uma vida, a qual gozaria da máxima proteção jurídica estatal, decorrente do princípio dignidade da pessoa humana. Pode-se afirmar ainda que a clonagem humana se trata de um crime vago ${ }^{11}$ (15), em que os sujeitos passivos - aqueles que têm seus bens jurídicos lesados - são indeterminados.

Além de vedar a clonagem humana, a Lei de Biossegurança também considera crime - cominando pena de detenção de um a três anos e multa - qualquer utilização de embrião humano em desacordo com o que dispõe o seu artigo $5^{\circ}$, ou seja, para que se consume tal delito basta, por exemplo, a utilização de embriões humanos congelados a menos de três anos para pesquisa ou que a utilização se dê sem a ciência e consentimento dos genitores.

\section{Conclusão}

O princípio da precaução faz da prudência um pressuposto para a realização de estudos em células-tronco embrionárias. Como consequência do princípio da precaução, visando a proteger a dignidade da pessoa humana, além do direito à individualidade genética, houve por bem o legislador brasileiro em vedar a realização de clonagem em seres humanos.

A realidade americana, com a permissão de patentes de linhagens de célulastronco embrionárias, vai na contramão dos postulados éticos, posto que corrobora com o fenômeno da patrimonialização da vida. Avançada, nesse ponto, a legislação brasileira, a qual, além de proibir referidas patentes, equipara ao crime de venda de órgãos a comercialização de células-tronco embrionárias.

O debate bioético ressurge num momento de cotejo entre desenvolvimento científico e preservação dos valores básicos da sociedade. O avanço da ciência é uma realidade da qual não se pode fugir. Destaque-se, entretanto, que o ser humano não deve ser utilizado como mero instrumento (16) de pesquisas, mas sim como a finalidade delas.

11. Damásio define crimes vagos como aqueles "que têm por sujeito passivo entidades sem personalidade jurídica, como a família, o público ou a sociedade”. 


\section{Referências}

1. Brasil. Lei no 11105 , de 24 de março de 2005 . Regulamenta os incisos II, IV e V do $\$ 1^{\circ}$. do art. 225 da Constituição Federal, estabelece normas de segurança e mecanismos de fiscalização de atividades que envolvam organismos geneticamente modificados - OGM e seus derivados, cria o Conselho Nacional de Biossegurança - CNBS, reestrutura a Comissão Técnica Nacional de Biossegurança - CTNBio, dispõe sobre a Política nacional de Biossegurança e dá outras providências. Diário Oficial da República Federativa do Brasil, DF, 26 mar., 2005.

2. Ferreira Filho RR. Principais Julgamentos do Supremo Tribunal Federal. Salvador: Juspodivm; 2009.

3. Brasil. Lei n ${ }^{\circ} 9434$, de 04 de fevereiro de 1997. Dispõe sobre a remoção de órgãos, tecidos e partes do corpo humano para fins de transplante e tratamento e dá outras providências. Diário Oficial da República Federativa do Brasil, DF, 05 fev., 1997.

4. Supremo Tribunal Federal. Coord. de Análise de Jurisprudência. ADPF n 54. http://www. stf.jus.br/portal/inteiroTeor/obterInteiroTeor.asp?numero=54\&classe=ADPF-QO (acesso em 31/05/2009)

5. Ferraz Júnior TS. Introdução ao Estudo do Direito: Técnica, Decisão, Dominação. $3^{a}$ ed. São Paulo, Atlas; 2001.

6. Brasil. Constituição da República Federativa do Brasil de 1988. Diário Oficial da República Federativa do Brasil, DF, 05 out., 1988.

7. Bonavides P. Curso de Direito Constitucional. 12ª ed. São Paulo: Malheiros; 2002.

8. Brasil. Decreto-Lei n 2848, de 07 de dezembro de 1940. Institui o Código Penal. Diário Oficial da República Federativa do Brasil, DF, 31 dez., 1940.

9. Brasil. Lei no 10406, de 10 de janeiro de 2002. Institui o Código Civil. Diário Oficial da República Federativa do Brasil, DF, 11 de jan., 2002.

10. Resta G. O Acesso ao material biológico humano com fins de pesquisa e de aproveitamento industrial: questões relativas ao consentimento e a responsabilidade no direito comparado. In: Costa JM, Möller LL, organizadoras. Bioética e Responsabilidade. Rio de Janeiro: Forense; 2009. p. 156-158.

11. Fernandes MS. Uma abordagem jurídica e bioética sobre as patentes envolvendo célulastronco humanas. In: Costa JM, Möller LL, organizadoras. Bioética e Responsabilidade. Rio de Janeiro: Forense; 2009. p. 236-297.

12. Brasil. Lei $n^{\circ}$ 9279, de 14 de maio de 1996. Regula Direito e Obrigações Relativos à Propriedade Industrial. Diário Oficial da República Federativa do Brasil, DF, 15 mai., 1996.

13. Trennepohl TD. Fundamentos de Direito Ambiental. $2^{\mathrm{a}}$ ed. Salvador: Juspodivm; 2007.

14. Machado PAL. Direito Ambiental Brasileiro. $17^{a}$ ed. São Paulo: Malheiros; 2009.

15. Jesus DE. Direito Penal: Parte Geral. 11ª ed. Saraiva: São Paulo; 1986.

16. Kant I. Fundamentação da Metafísica dos Costumes e Outros Escritos. São Paulo: Martin Claret; 2004.

Recebido: 15/06/2011 Aprovado: 27/11/2011 